\section{FRI0500 AVOIDANCE OF PHYSICAL ACTIVITY LEADS TO REDUCED INFLAMMATORY ENTHESITIS ON ULTRASOUND}

K. Wervers ${ }^{1}$, I. Herrings ${ }^{1}$, J.J. Luime ${ }^{1}$, M. Moed ${ }^{1}$, I. Tchetverikov ${ }^{2}$, A.H. Gerards ${ }^{3}$, J.M.W. Hazes ${ }^{1}$, M. Vis ${ }^{1} .{ }^{1}$ Rheumatology, Erasmus MC

Rotterdam; ${ }^{2}$ Rheumatology, Albert Schweitzer Hospital, Dordrecht;

${ }^{3}$ Rheumatology, Vlietland Hospital, Schiedam, Netherlands

Background: Enthesitis is one of the manifestations of psoriatic arthritis (PsA), but no clear definition for the diagnosis exists. To further evaluate the added value of sonographic evaluation of entheses in diagnosing enthesitis, more knowledge on factors associated with sonographic enthesitis is needed.

Objectives: We aim to evaluate which clinical characteristics are associated with sonographic enthesitis changes in a cross-sectional PsA population.

Methods: established PsA patients were asked to participate, irrespective of enthesitis complaints. Patients were interviewed on history of musculoskeletal complaints (MSC), more specifically if they had complaints during activities and whether they avoided physical activities (during exercise, work, household tasks, hobbies, chores). Tenderness was determined in the MASEl entheses and those in the Leeds Enthesitis Index (LEI) and Maastricht Ankylosing Spondylitis Enthesitis Score (MASES). Previously we showed that a modified Madrid Sonographic Enthesitis Index (MASEl, i.e. excluding knee enthesis thickness and scoring PD-signal semi-quantitatively) distinguishes entheses of PsA patients from those of healthy volunteers (1). A sonographist unaware of clinical findings scored the modified MASEI. Multivariable linear regressions of structural (erosions, calcifications, structure) and inflammatory (thickness, bursitis and PD) modified MASEI scores were performed (transformed for a better distribution). Variables included age, gender, PsA duration, medication use (non/nsaids vs. sDMARDs vs. bDMARDs), LEI + MASES and avoidance (no vs. yes)

Results: 84 PsA patients participated (45 males, mean age 55, median disease duration 8 years). Median modified MASEI was 12 (IQR 7.25-17), with a structural component score of $7(3-10)$ and inflammatory component score of 6 (3.5-8.5). 8 patients used no medication or NSAIDs only, 36 used sDMARDs and 40 used bDMARDs. 45 patients reported avoiding activities. In a multivariable analysis, inflammatory modified MASEI was negatively associated with avoidance (i.e. fewer inflammatory changes in patients reporting avoidance) and positively associated with age, BMI and use of biologics. Structural MASEI was positively associated with age only.

Table 1. Univariable and multivariable linear regression analysis of inflammatory and structural summary scores of MASEI

\begin{tabular}{|c|c|c|c|c|c|c|c|c|}
\hline \multirow[b]{3}{*}{ age } & \multicolumn{4}{|c|}{ inflammatory modified MASE } & \multicolumn{4}{|c|}{ structural modified MASEI } \\
\hline & \multicolumn{2}{|c|}{ Univariable } & \multicolumn{2}{|c|}{ Multivariable } & \multicolumn{2}{|c|}{ Univariable } & \multicolumn{2}{|c|}{ Multivariable } \\
\hline & 0.018 & {$[0.005 ; 0.031]$} & 0.015 & {$[0.002 ; 0.029]$} & 0.034 & {$[0.017 ; 0.051]$} & 0.032 & {$[0.013,0.051]$} \\
\hline gender (female vs. male) & 0.156 & & 0.162 & & 0.122 & & 0.102 & \\
\hline BMI & 0.030 & & 0.031 & {$[0.002 ; 0.060]$} & 0.041 & & 0.039 & \\
\hline \multicolumn{9}{|l|}{ medication use } \\
\hline none/nsaids vs. sDMARDS & 0.365 & & 0.349 & & 0.690 & & 0.463 & \\
\hline none/nsaids vs. bDMARDs & 0.484 & & 0.588 & {$[0.076 ; 1.100]$} & 0.588 & & 0.462 & \\
\hline sqrt(disease duration) & 0.085 & & -0.021 & & 0.246 & {$[0.030-0.462]$} & 0.110 & \\
\hline LEI + MASES & -0.006 & & -0.005 & & 0.016 & & -0.005 & \\
\hline avoidance (no vs. Yes) & -0.415 & {$[-0.710 ; 0.119]$} & -0.40 & {$[-0.697 ;-0.094]$} & -0.012 & & 0.131 & \\
\hline
\end{tabular}

Conclusions: Avoiding physical activities is associated with fewer inflammatory changes of the entheses. More inflammatory changes are seen in older or overweight patients and patients on biologicals, in the latter possibly due to more active disease.

\section{References:}

[1] Wervers K, Rasappu N, Vis M, Tchetverikov I, Kok MR, Gerards AH, et al. AB0733 Masei Shows Substantial Changes in The Entheses of Young Healthy Volunteers - Amending Its PD Score and Excluding Knee Entheses Thickness Provides Better Discrimination of Enthesitis in Psoriatic Arthritis Patients. Ann Rheum Dis 2016;75:1155

Disclosure of Interest: None declared

DOI: 10.1136/annrheumdis-2017-eular.3471

\section{FRI0501 REAL-WORLD USE OF SECUKINUMAB IN PATIENTS WITH PSORIATIC ARTHRITIS IN THE UNITED STATES: PATIENT PROFILE AND DOSING REGIMEN USE}

K. Oelke ${ }^{1}$, G. Chun ${ }^{2}$, Y. Li ${ }^{2}$, X. Liu ${ }^{3}$, J.B. Palmer ${ }^{2}{ }^{1}$ Rheumatic Disease Center, Glendale; ${ }^{2}$ Novartis Pharmaceuticals Corporation, East Hanover; ${ }^{3}$ KMK Consulting, Inc, Morristown, United States

Background: As of January 15, 2016, secukinumab became the first fully human anti-interleukin-17 monoclonal antibody approved for the treatment of patients with psoriatic arthritis (PsA) in the United States. Secukinumab may be administered with or without loading of $150 \mathrm{mg}$ or $300 \mathrm{mg}$ (patients with concomitant moderate to severe psoriasis only) at weeks $0,1,2,3$ and 4 followed by maintenance dosing every 4 weeks. The use of a loading regimen of secukinumab in a real-world setting of patients with PsA has not been evaluated since its approval in the United States.

Objectives: To better understand the real-world use of secukinumab by describing the demographic, clinical and treatment characteristics (loading vs no loading) of secukinumab-treated patients with PsA.

Methods: Retrospective data from the Symphony Health Solutions Lx commercial claims database were used to identify patients who had $\geq 1$ secukinumab claim between $01 / 15 / 2016$ and 06/30/2016. Patients who were included in the analysis were aged $\geq 18$ years, had $\geq 1$ ICD-9 code of 696.0 or ICD-10 code of L40.5 for PsA and had $\geq 1$ pharmacy or medical claim in the 12 months prior to their first secukinumab claim (index date). Patient demographics and secukinumab dosage were examined at the index date. Clinical characteristics, comorbidities and treatment history in the 12 months prior to the index date were identified and presented by use vs no use of loading.

Results: A total of 764 patients met the inclusion criteria. The mean (SD) age was 50.7 (11.6) years, $58.5 \%$ of patients were female and $39.8 \%$ of patients were from the south. The most common specialties prescribing secukinumab to patients with PsA were rheumatologists $(52.1 \%)$ and dermatologists $(30.0 \%)$. A total of 608 patients $(79.6 \%)$ received loading and $156(20.4 \%)$ did not; at the index date, the majority of patients received secukinumab at the $300-\mathrm{mg}$ dose in the loading $(73.2 \%)$ and no loading $(84.6 \%)$ groups. Patient demographics, clinical characteristics and treatment history were generally comparable between groups (Table 1). However, more patients with loading had prior oral corticosteroid (OCS; $30.9 \%$ vs $20.5 \%$ ), targeted synthetic disease-modifying antirheumatic drug (tsDMARD; $24.7 \%$ vs $17.3 \%$ ) and biologic $(64.3 \%$ vs $59.6 \%$ ) use compared with those without loading. The most prevalent comorbidities were psoriasis $(58.8 \%)$, hypertension (34.4\%) and hyperlipidemia (26.8\%). A higher proportion of patients with loading had hypertension (35.2\% vs $31.2 \%$ ), rheumatoid arthritis (RA; $15.3 \%$ vs $10.9 \%$ ), fatigue $(13.5 \%$ vs $9.0 \%)$ and anxiety $(13.3 \%$ vs $8.3 \%)$ and a lower proportion had psoriasis $(57.4 \%$ vs $64.1 \%$ ) compared with those without loading.

\begin{tabular}{|c|c|c|c|}
\hline & $\begin{array}{c}\text { Overall } \\
(n=764)\end{array}$ & $\begin{array}{l}\text { Loading } \\
(\mathrm{n}=608)\end{array}$ & $\begin{array}{l}\text { No Loading } \\
(n=156)\end{array}$ \\
\hline Age, mean (SD), years & $50.7(11.6)$ & $50.9(11.9)$ & $49.9(10.5)$ \\
\hline Female, $\mathrm{n}(\%)$ & $447(58.5)$ & $358(58.9)$ & $89(57.1)$ \\
\hline \multicolumn{4}{|l|}{ Region, $n(\%)$} \\
\hline South & $304(39.8)$ & $251(41.3)$ & $53(34.0)$ \\
\hline Northeast & $203(26.6)$ & $153(25.2)$ & $50(32.1)$ \\
\hline Midwest & $152(19.9)$ & $118(19.4)$ & $34(21.8)$ \\
\hline West & $104(13.6)$ & $85(14.0)$ & $19(12.2)$ \\
\hline \multicolumn{4}{|l|}{ Physician specialty, $n(\%)$} \\
\hline Rheumatology & $398(52.1)$ & $319(52.5)$ & $79(50.6)$ \\
\hline Dermatology & $229(30.0)$ & $176(28.9)$ & $53(34.0)$ \\
\hline \multicolumn{4}{|l|}{ Index dose, $n(\%)$} \\
\hline $150 \mathrm{mg}$ & $187(24.5)$ & $163(26.8)$ & $24(15.3)$ \\
\hline $300 \mathrm{mg}$ & $577(75.5)$ & $445(73.2)$ & $132(84.6)$ \\
\hline \multicolumn{4}{|l|}{ Treatment history, $\mathrm{n}(\%)$} \\
\hline NSAID & $159(20.8)$ & $124(20.4)$ & $35(22.4)$ \\
\hline Oral corticosteroid & $220(28.8)$ & $188(30.9)$ & $32(20.5)$ \\
\hline CSDMARD & $265(34.7)$ & $210(34.5)$ & $55(35.3)$ \\
\hline tsDMARD & $177(23.2)$ & $150(24.7)$ & $27(17.3)$ \\
\hline Biologic & $484(63.4)$ & $391(64.3)$ & $93(59.6)$ \\
\hline Adalimumab & $167(21.9)$ & $134(22.0)$ & $33(21.2)$ \\
\hline Ustekinumab & $166(21.7)$ & $136(22.4)$ & $30(19.2)$ \\
\hline Etanercept & $122(16.0)$ & $98(16.1)$ & $24(15.4)$ \\
\hline Certolizumab & $65(8.5)$ & $52(8.6)$ & $13(8.3)$ \\
\hline Infliximab & $55(7.2)$ & $46(7.6)$ & $9(5.8)$ \\
\hline Golimumab & $38(5.0)$ & $34(5.6)$ & $4(2.6)$ \\
\hline \multicolumn{4}{|l|}{ Comorbidities, n (\%) } \\
\hline Psoriasis & $449(58.8)$ & $349(57.4)$ & $100(64.1)$ \\
\hline Hypertension & $263(34.4)$ & $217(35.2)$ & $49(31.2)$ \\
\hline Hyperlipidemia & $205(26.8)$ & $161(26.5)$ & $44(28.2)$ \\
\hline Other skin diseases & $189(24.7)$ & $149(24.5)$ & $40(25.6)$ \\
\hline Cancer & $152(19.9)$ & $118(19.4)$ & $34(21.8)$ \\
\hline Diabetes & $143(18.7)$ & $113(18.6)$ & $30(19.2)$ \\
\hline Depression & $125(16.4)$ & $98(16.1)$ & $27(17.3)$ \\
\hline Obesity & $117(15.3)$ & $96(15.8)$ & $21(13.5)$ \\
\hline Rheumatoid arthritis & $110(14.4)$ & $93(15.3)$ & $17(10.9)$ \\
\hline Fatigue & $96(12.6)$ & $82(13.5)$ & $14(9.0)$ \\
\hline Anxiety & $94(12.3)$ & $81(13.3)$ & $13(8.3)$ \\
\hline
\end{tabular}

Conclusions: This US claims-based study found the majority $(\approx 73 \%)$ of secukinumab-treated patients with PsA were initiated with a loading regimen. Most patients initiated the $300-\mathrm{mg}$ dose regardless of loading. A higher proportion of patients with loading had prior OCS, tsDMARD and biologic use, as well as hypertension, RA, fatigue and anxiety compared with those without loading, suggesting patients who initiated with loading had more refractory disease. These results provide the first insights into real-world use of secukinumab with and without loading in patients with PsA in the United States.

Acknowledgements: This study was sponsored by Novartis Pharmaceuticals Corporation, East Hanover, NJ.

Disclosure of Interest: K. Oelke Consultant for: Novartis, Speakers bureau: Amgen, AbbVie, Bristol-Meyers Squibb, Pfizer, G. Chun Employee of: Novartis, Y. Li Employee of: Novartis, X. Liu Consultant for: Novartis, Employee of: KMK Consulting, Inc, J. Palmer Employee of: Novartis

DOI: 10.1136/annrheumdis-2017-eular.154 